\title{
Evaluation of the Inflammatory Reaction in Calves with Acute Ruminal Drinking
}

\author{
Maged El-Ashker ${ }^{1 *}$, Mahmoud El-Sebaei², and Mohamed Salama²
}

${ }^{1}$ Department of Internal Medicine and Infectious Diseases, Faculty of Veterinary Medicine, Mansoura University, Mansoura 35516, Egypt

${ }^{2}$ Department of Biochemistry \& Chemistry of Nutrition, Faculty of Veterinary Medicine, Mansoura University, Mansoura 35516, Egypt

\begin{abstract}
The present study was carried out to evaluate the inflammatory response during acute ruminal drinking in milkfed calves and to describe the correlation between production of acute phase cytokines and the occurrence of depression in this clinical condition. For this purpose, twenty calves with acute ruminal drinking as well as ten clinically normal calves were included in the study. Blood and ruminal fluid samples were collected from all examined calves. The blood samples were used to obtain a blood gas profile and for estimation of selected acute phase proteins and pro-inflammatory cytokines. A depression score was adopted to emphasize the relationship between the severity of the clinical signs and levels of acute phase cytokines. It was found that interleukin-1beta; interleukin-6, interferon gamma, $c$ reactive protein, haptoglobin, and fibrinogen were significantly higher in diseased calves compared to the control group. There was also a positive correlation between the depression score and the examined acute phase cytokines. Our findings suggest that the acidity of the rumen Leads to inflammation of papillae with subsequent distinct inflammatory reaction. It seems that the pro-inflammatory cytokines play a role in the pathogenesis of acute ruminal drinking in milk-fed calves.
\end{abstract}

Keywords: Acute phase proteins; Cytokines; Calves; Ruminal drinking

\section{Introduction}

In the past two decades, ruminal drinking (RD) in milk-fed calves has drawn the attention of many scientists all over the world [1-4]. $\mathrm{RD}$ is most common in 2 to 8 week old bucket-fed calves. Calves that "gulp" rather than sip milk are at the greatest risk [5]. RD occurs when dysfunction of the esophageal groove reflex allows milk to spill into the reticulo-rumen instead of being delivered directly into the abomasum [6]. As a result, the milk retained in the rumen undergoes fermentation and acetic acid, butyric acid and lactic aid are produced, with a subsequent fall in the ruminal $\mathrm{pH}$ and the development of dyskeratosis of the ruminal mucosa. Indeed, lactic acid is the most detrimental product that is produced by bacterial fermentation of the carbohydrate fraction of the milk [3,7]. The cause of metabolic alterations in this case the absorption of both $\mathrm{D}$ and $\mathrm{L}$ isomers of lactic acid formed in the rumen. However, due to the different metabolic pathways, only D-lactate tends to accumulate in the blood [8]. Secondary changes due to $\mathrm{RD}$ include villous atrophy in the small intestine and reduced disaccharidase activity of the brush border [5].

There are two different forms of fermentative ruminal acidosis in calves, an acute and a chronic form. In the acute form, dysfunction of the esophageal groove is usually superimposed on another pre-existent pathological condition. This acute and sometimes severe form is typical in young calves fed cow's milk in buckets during their first weeks of life [9]. In the chronic form, dysfunction of the esophageal groove occurs as results of stressful situations such as prolonged transportation to assembly centers and onwards to fattening units or new groupings [7]. Calves with acute $\mathrm{RD}$ appear to be in pain, depressed, reluctant to move and anorectic with varying degrees of abdominal distension. They also pass sticky, clay-like feces that may adhere to the tail, perineum, and hind legs $[3,5]$.

The body's overall response to inflammation is a complicated process involving gene expression, protein production, and changes in physiologic responses, that together form what is known as the acute phase response (APR) [10]. The APR is regulated by numerous compounds referred to as cytokines [10-12]. The latter are produced by macrophages, when they are activated by bacterial endotoxins, viruses, free radicals, prostaglandins, or other factors released under different inflammatory conditions. The main cytokines released by macrophages are interleukin-1 (IL-1), interleukin-8, tumor necrosis factor-alpha (TNF- $\alpha$ ), and interferon-gamma (INF- $\gamma$ ) $[11,12]$. The release of proinflammatory cytokines at the site of tissue injury stimulates various other cell types to produce a cascade of other cytokines, including interleukin-6 (IL-6), which act to stimulate the production of acute phase proteins (APPs) from the hepatocytes or other tissues [10]. Although the production of cytokines in the liver or other local sites is a multifaceted process, it is believed that IL- 1 and IL- 6 are the two main stimulants of APP production [13]. In mice, it was reported that the immune system in uses interleukin- 1 beta (IL-1 $\beta), \mathrm{IL}-6$, and TNF- $\alpha$ to convey information to the brain about the level of immunological activity. If macrophages are unable to produce cytokines when exposed to inflammatory stimuli (e.g. lipopolysaccharide), the immune system cannot communicate with other systems and the animals do not behave sick as they would otherwise [14]. Up to now, most RD studies have dealt with the etiology, pathogenesis and associated acidbase disturbances $[4,14,15]$. However, to our knowledge, there are no published articles that describe the changes in acute phase cytokines in calves with acute RD. Therefore, the present study was carried out to evaluate the inflammatory response during acute $\mathrm{RD}$ in milk-fed calves

*Corresponding author: Maged El-Ashker, Department of Internal Medicine and Infectious Diseases, Faculty of Veterinary Medicine, Mansoura University, Mansoura 35516, Egypt, Tel: +4917658898006; Fax: +2-050-2379952; E-mail: maged_elashker@yahoo.com

Received May 16, 2012; Accepted July 10, 2012; Published July 13, 2012

Citation: El-Ashker M, El-Sebaei2, Salama M (2012) Evaluation of the Inflammatory Reaction in Calves with Acute Ruminal Drinking. J Vet Sci Technol 3:116 doi:10.4172/2157-7579.1000116

Copyright: (c) 2012 El-Ashker M, et al. This is an open-access article distributed under the terms of the Creative Commons Attribution License, which permits unrestricted use, distribution, and reproduction in any medium, provided the original author and source are credited. 
and to describe the possible correlation between cytokine production and occurrence of depression in this clinical condition.

\section{Materials and Methods}

\section{Study population and case definition}

In 2011, 91 mixed breed, 3 to 6 week old calves with symptoms of RD were examined. The calves were from three private farms in Dakahlia Governorate, Egypt. The inclusion criteria included calves with acute RD on the basis of case history (force feeding while calves being anorectic), clinical examinations (depression, reluctance to move, varying degrees of dehydration, frequent recumbency, left sided abdominal distension, teeth grinding, splashing sound on ballottement and ping sound on finger percussion over the left flank region and the characters of the obtained ruminal fluid), as well as laboratory investigation (metabolic acidosis). Criteria for the diagnosis of metabolic acidosis were venous blood $\mathrm{pH}<7.35$ and bicarbonate $\left(\mathrm{HCO}_{3}{ }^{-}\right)$concentration $<24 \mathrm{mmol} / \mathrm{L}$.

Claves with chronic RD were identified on the basis of case history (transportation or grouping, absence of forced feeding, long course may be few weeks), and characteristic clinical signs like retarded growth, poor suckling reflex, recurrent tympany specially after milk feeding, dry hair coat and widespread alopecia, ventral abdominal distension and typical plunging sound of milk flowing into the fluid filled rumen detected while auscultation of the left flank region during milk suckling. Consequently, a total of $20(33.0 \pm 1.6)$ day old calves were enrolled in this study. However, calves with chronic RD as well as those with clinical evidence of concurrent illness (enteritis, abomasal dilatation, septicemia, omphalitis, arthritis and respiratory troubles) were excluded $(\mathrm{n}=71)$. The selection criteria were applied aiming to exclude as many calves as possible with concomitant disturbances or diseases that could affect the general condition and hence the parameters under study. For comparison, ten clinically healthy $(29.0 \pm 2.0)$ day old calves from the same population were randomly selected and served as a control group.

\section{Clinical examinations}

A detailed clinical examination was performed for all calves. Among the common clinical parameters, particular attention was given to sensorium, suckling reflex, skin turgor, eyeball position, rectal temperature, heart rate, respiratory rate, appetite and feces characteristics. Once acute RD was tentatively diagnosed, a numerical scoring system (depression score) was adopted immediately before collection of blood samples as described in a previous study [16]. Briefly, the depression score was based on dehydration (enophthalmia), neurologic (suckling reflex, menace reflex, tactile response, ability to stand) and cardiovascular (warmth of oral cavity and extremities) signs. The variable scores were summarized to yield a minimum score of zero in clinically healthy calves and a maximum score of 15 in severely affected calves. The hydration status was assessed by observing the eye ball and its position in the orbit together with skin turgor test applied over the upper eyelid. The suckling reflex was assessed by inserting the finger in the mouth. Menace reflex was assessed by rapid hand movement toward the eye; whereas, the tactile response was performed through pinching the skin over the lumbar area while observing the calves' reactions.

\section{Sampling and measurements}

Blood samples: Blood samples were collected from clinically healthy calves and those with acute $\mathrm{RD}$ through jugular vein puncture into heparinized and plain tubes. Heparinized samples were divided into two aliquots. The first aliquot was used for measuring blood $\mathrm{pH}$, partial pressure of carbon dioxide tension $\left(\mathrm{pCO}_{2}\right)$, partial pressure of oxygen tension $\left(\mathrm{pO}_{2}\right)$, and calculating acid base parameters as $\mathrm{HCO}_{3}$ and base excess (BE) by using the blood gas analyzer AVL 995- Hb (AVL List GmbH Medizintechnik distributed by AVL Medical Instruments UK Ltd). The values of $\mathrm{pH}$ and $\mathrm{pCO}_{2}$ were automatically corrected to correspond to the calf's rectal temperature. Blood electrolytes such as sodium, potassium and chloride were also measured using an electrolyte analyzer AVL 984-S (AVL List GmbH Medizintechnik distributed by AVL Medical Instruments UK Ltd). The anion gap (AG) was then calculated based on the equation $\mathrm{AG}=\left(\mathrm{Na}^{+}+\mathrm{K}^{+}\right)-\left(\mathrm{Cl}^{-}+\mathrm{HCO}_{3}^{-}\right)$. Blood L-lactate levels were spectrophotometrically estimated using a commercial kit (Sigma Diagnostics, St Louis, Mo, USA) according to the manufacturer's instructions.

The second blood aliquot was rapidly centrifuged $10 \mathrm{~min}$ at 3,000 $\times \mathrm{g}$ for separation of plasma. The plasma was used for estimation of $c$ reactive protein (CRP), haptoglobin (Hp) and fibrinogen using the K-Assay kit (Kamiya Biomedical Company, WA, USA) by the full automated chemical analyzer Hitachi 917 (Roche Diagnostics, Germany) according to the manufacturer's instructions. The lower detection limits of CRP and Hp and fibrinogen were $0.1 \mathrm{mg} / \mathrm{L}, 20 \mathrm{mg} / \mathrm{L}$ and $81 \mathrm{mg} / \mathrm{dl}$, respectively. Blood collected in plain tubes was left to clot and then centrifuged at 3,000 g for $10 \mathrm{~min}$. Only non-hemolyzed sera were harvested and kept frozen at $-20^{\circ} \mathrm{C}$ until the analysis of TNF- $\alpha$, IL- $1 \beta$, IL- 6 and IF- $\gamma$. Based on the approach of some authors $[17,18]$, who recorded a cross reactivity between cow, horse, human, and mouse cytokines, the previously mentioned cytokines were determined from undiluted serum samples using commercially available human ELISA Kits (Biosurce, Diagnostic Corporation, Belgium). The plates were read at $450 \mathrm{~nm}$ and a correction wavelength of $550 \mathrm{~nm}$ was measured on a computerized automated microplate ELISA reader (Bio TEC, ELX800G, USA). Values expressed in picograms per milliliter (pg/ $\mathrm{mL}$ ) were extrapolated using linear regression from a standard curve of known amounts of human cytokines.

Ruminal fluid analysis: Ruminal fluid was siphoned from clinically healthy calves and those with acute RD using a nasogastric tube. Besides $\mathrm{pH}$; color, smell, consistency and presence of casein coagula or other particles were observed. Ruminal fluid $\mathrm{pH}$ was determined using a $\mathrm{pH}$ paper within $30 \mathrm{~min}$ of sample collection after large particulate matter had been strained from the fluid by using cheesecloth. The color reaction was extrapolated to the nearest $1 \mathrm{pH}$ unit.

Medical management: The diseased calves were managed by siphoning of the ruminal content through a nasogastric tube and the ruminal cavity was repeatedly flushed with 1-2 liters of warm tap water adjusted to the calf's body temperature until the contents have lost their sour smell. If the ruminal fluid $\mathrm{pH}$ remained acidic following ruminal lavage, milk was withheld for two consecutive days. During this fasting period, calves were received IV fluid therapy every 24 hours depending on the severity of metabolic alterations. The administered infusions consisted of isotonic sodium bicarbonate 1.3\% (The Egyptian Company for Chemical and Pharmaceutical), isotonic physiological saline $0.9 \%$ and hypertonic glucose solution 25\% (Misr Company for Pharmaceuticals and Chemical).

\section{Statistical Analysis}

Data were statistically analyzed for significant differences $(\mathrm{p}<0.05)$ using Student's t-test by Graph Pad Prism software (Graph Pad software Inc., San Diego). For hematological and biochemical parameters, data were tested for normality of distribution using D'Agostino and Pearson Omnibus normality test. Means and standard errors of means (SEM) 


\begin{tabular}{|c|c|c|}
\hline Variable & Diseased calves & Control calves \\
\hline \multicolumn{3}{|l|}{ Enophthalmia } \\
\hline None & $n=0$ & $n=10$ \\
\hline Slight & $n=10$ & \\
\hline marked & $n=10$ & \\
\hline \multicolumn{3}{|l|}{ Suckling reflex } \\
\hline Normal & $n=2$ & $n=10$ \\
\hline Absent & $n=5$ & \\
\hline Weak coordinated & $n=5$ & \\
\hline Disorganized & $n=8$ & \\
\hline \multicolumn{3}{|l|}{ Menace reflex } \\
\hline Normal & $n=0$ & $n=10$ \\
\hline Instantaneous & $n=2$ & \\
\hline delayed & $n=12$ & \\
\hline Absent & $n=6$ & \\
\hline \multicolumn{3}{|l|}{ Tactile response } \\
\hline Skin twitch, head movement & $n=3$ & $n=10$ \\
\hline Skin twitch, no head movement & $n=12$ & \\
\hline No skin twitch, no head movement & $n=5$ & \\
\hline \multicolumn{3}{|l|}{ Ability to stand } \\
\hline Ability to stand unassisted & $n=13$ & $n=10$ \\
\hline Inability to stand unassisted & $\mathrm{n}=7$ & \\
\hline \multicolumn{3}{|l|}{ Temperature of the oral mucosa } \\
\hline Normal & $n=6$ & $n=10$ \\
\hline Cool & $n=10$ & \\
\hline Cold & $n=4$ & \\
\hline \multicolumn{3}{|l|}{ Warmth of extremities } \\
\hline Normal & $n=6$ & $n=10$ \\
\hline Cool & $n=10$ & \\
\hline Cold & $n=4$ & \\
\hline \multicolumn{3}{|l|}{ Teeth grinding } \\
\hline Absent & $n=4$ & $n=10$ \\
\hline Present & $n=16$ & \\
\hline \multicolumn{3}{|l|}{ Abdominal distention } \\
\hline None & $n=0$ & $n=10$ \\
\hline Slight & $n=4$ & \\
\hline Moderate & $n=16$ & \\
\hline \multicolumn{3}{|l|}{ Ballottement of the left flank } \\
\hline No sound & $n=0$ & $n=10$ \\
\hline Loud splashing sound* & $n=20$ & \\
\hline \multicolumn{3}{|l|}{ Finger percussion over the left flank } \\
\hline No sound & $n=0$ & $n=10$ \\
\hline Ping sound & $n=20$ & \\
\hline
\end{tabular}

${ }^{*}$ Can be heard without a stethoscope

Table 1: Clinical findings in 20 calves with acute ruminal drinking compared to 10 healthy calves.

for each variable were estimated. Spearman correlation coefficient was also applied to emphasize the correlation between depression score, blood L-lactate and the examined pro-inflammatory markers.

\section{Results}

The clinical characteristics of the diseased and clinically healthy calves as well as the results of blood gases and other biochemical variables are summarized in Tables 1-3. In calves with acute $\mathrm{RD}$, depression scores varied from 1 to 15 (mean $8.20 \pm$ SD 4.40); however, it was zero in clinically healthy calves. All diseased calves were in a moderate physical condition and defecated sticky, clay-like feces adhered to the tail and perineum. All diseased calves showed varying degrees of enophthalmia and depression. In calves with slight to moderate depression, varying degrees of ataxia were observed and they were able to stand unassisted. In those with severe depression, profound weakness was recorded and they were unable to stand unassisted and preferred to be in a recumbent position. The majority of the diseased calves showed a delayed or absent menace reflex.

The depression score of the diseased calves was positively correlated with blood lactate $(r=0.94 ; p<0.01), A G(r=0.78 ; p<0.01), I L-1 \beta(r=0.99$, $\mathrm{p}<0.01)$, IL-6 $(\mathrm{r}=0.95, \mathrm{p}<0.01)$, IF- $\gamma(\mathrm{r}=0.64 \mathrm{p}<0.01)$, CRP $(\mathrm{r}=0.88$, $\mathrm{p}<0.01)$, fibrinogen $(\mathrm{r}=0.90, \mathrm{p}<0.01)$, and $\mathrm{Hp}(\mathrm{r}=0.93, \mathrm{p}<0.0001)$, while it was negatively correlated with blood $\mathrm{pH}(\mathrm{r}=-0.89 ; \mathrm{p}<0.01), \mathrm{pCO}$ $(\mathrm{r}=-0.80 ; \mathrm{p}<0.01), \mathrm{HCO}_{3}^{-}(\mathrm{r}=-0.88, \mathrm{p}<0.01), \mathrm{pO}_{2}(\mathrm{r}=-0.66, \mathrm{p}<0.01), \mathrm{BE}$ $(\mathrm{r}=-0.72, \mathrm{p}<0.01), \mathrm{Na}^{+}(\mathrm{r}=-0.50, \mathrm{p}<0.011)$, and $\mathrm{Cl}^{-}(\mathrm{r}=-0.51, \mathrm{p}<0.01)$ Biochemically, blood IL- $1 \beta$, IL-6, IF- $\gamma$, CRP, Hp, and fibrinogen were significantly higher in diseased calves compared to the control group (Table 2). Metabolic acidosis was apparent in the diseased calves compared to the control group, confirmed by a significant decrease in blood $\mathrm{pH}, \mathrm{HCO}_{3}^{-}$, and $\mathrm{BE}$, as well as a compensatory respiratory mechanism indicated by a significant decrease in $\mathrm{pCO}_{2}$ (Table 3). Mean values of AG and blood L-lactate were significantly increased in diseased calves compared to healthy ones, while plasma sodium and chloride values were significantly decreased.

Blood L-lactate levels were found to be positively correlated with IL-1 $\beta(r=0.79, p<0.05)$, IF- $\gamma(r=0.89, p<0.01), H p(r=0.63, p<0.001)$ CRP $(r=0.54, p<0.009)$, fibrinogen $(r=0.67, p<0.001)$, while it was negatively correlated with blood $\mathrm{pH}(\mathrm{r}=-0.75, \mathrm{p}<0.05)$, HCO3- $(\mathrm{r}=-0.81$, $\mathrm{p}<0.019 ; \mathrm{BE}(\mathrm{r}=-0.65, \mathrm{p}<0.05)$. In clinically healthy calves, ruminal juice had a light beige colour, musty or stale smell, a watery consistency and a $\mathrm{pH}$ of $6.80 \pm 0.23$. However, in those with acute $\mathrm{RD}$, the ruminal fluid usually had a milk-like appearance with milk coagulum (Figure 1). Moreover, it had a pungent, sour smell and a pH of $3.72 \pm 1.10$.

\begin{tabular}{|l|l|l|l|}
\hline Variables & Control & Diseased calves & P Value \\
\hline TNF- $\alpha(\mathrm{pg} / \mathrm{mL})$ & $12.90 \pm 0.76$ & $13.04 \pm 0.31$ & 0.8763 \\
\hline $\mathrm{IL}-1 \beta(\mathrm{pg} / \mathrm{mL})$ & $13.43 \pm 0.34$ & $18.85 \pm 0.48$ & 0.0004 \\
\hline $\mathrm{IL}-6(\mathrm{pg} / \mathrm{mL})$ & $17.77 \pm 0.41$ & $26.19 \pm 0.95$ & 0.0030 \\
\hline $\mathrm{IF}-\mathrm{Y}(\mathrm{pg} / \mathrm{mL})$ & $9.27 \pm 0.18$ & $12.81 \pm 0.25$ & $<0.0001$ \\
\hline CRP $(\mathrm{mg} / \mathrm{L})$ & $29.67 \pm 0.06$ & $517.80 \pm 0.12$ & $<0.0001$ \\
\hline Fibrinogen $(\mathrm{mg} / \mathrm{dL})$ & $411.7 \pm 22.42$ & $502.5 \pm 4.11$ & $<0.0001$ \\
\hline Hp $(\mathrm{g} / \mathrm{L})$ & $0.11 \pm 0.01$ & $2.44 \pm 0.21$ & $<0.0001$ \\
\hline
\end{tabular}

TNF- $\alpha$ Tumour necrosis factor alpha; IL-1 $\beta$ Interleukin 1 beta; IL-6 Interleukin 6 ; IF-y Interferon gamma; CRP C reactive protein; Hp Haptoglobin

Table 2: Mean values \pm SEM of selected pro-inflammatory markers and acute phase proteins in 10 clinically healthy calves and 20 calves with acute ruminal drinking.

\begin{tabular}{|l|l|l|l|}
\hline Variables & Control & Diseased calves & $\mathrm{P}$ Value \\
\hline $\mathrm{pH}$ & $7.392 \pm 0.02$ & $7.24 \pm 0.01$ & $<0.0001$ \\
\hline $\mathrm{PCO}_{2}(\mathrm{mmHg})$ & $40.84 \pm 1.84$ & $30.85 \pm 0.67$ & $<0.0001$ \\
\hline $\mathrm{PO}_{2}(\mathrm{mmHg})$ & $39.80 \pm 0.80$ & $35.95 \pm 0.59$ & 0.0053 \\
\hline $\mathrm{HCO}_{3}^{-}(\mathrm{mmol} / \mathrm{L})$ & $25.40 \pm 1.12$ & $17.00 \pm 0.52$ & $<0.0001$ \\
\hline $\mathrm{BE}(\mathrm{mmol} / \mathrm{L})$ & $1.08 \pm 0.77$ & $-6.150 \pm 1.10$ & 0.0029 \\
\hline Sodium $(\mathrm{mmol} / \mathrm{L})$ & $136.4 \pm 1.17$ & $131.40 \pm 1.52$ & $<0.0001$ \\
\hline Potassium $(\mathrm{mmol} / \mathrm{L})$ & $4.70 \pm 0.29$ & $3.920 \pm 0.25$ & 0.1442 \\
\hline Chloride $(\mathrm{mmol} / \mathrm{L})$ & $102.0 \pm 0.84$ & $98.25 \pm 2.13$ & 0.0064 \\
\hline AG $(\mathrm{mmol} / \mathrm{L})$ & $13.40 \pm 2.19$ & $19.70 \pm 3.36$ & 0.0027 \\
\hline L-Lactate $(\mathrm{mmol} / \mathrm{L})$ & $1.34 \pm 0.12$ & $3.965 \pm 0.23$ & $<0.0001$ \\
\hline
\end{tabular}

$\mathrm{PCO}_{2}$ partial pressure of carbon dioxide tension; $\mathrm{PO}_{2}$ partial pressure of oxygen tension; $\mathrm{HCO}_{3}^{-B l o o d ~ b i c a r b o n a t e ; ~ B E ~ B a s e ~ e x c e s s ; ~ A G ~ A n i o n ~ g a p ~}$

Table 3: Mean values \pm SEM of blood gases and acid-base parameters in 10 clinically healthy calves and 20 calves with acute ruminal drinking. 


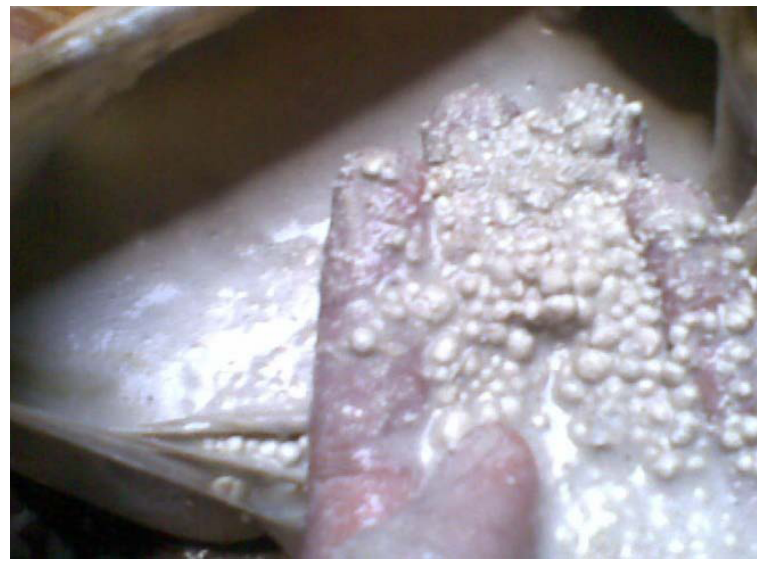

Figure 1: Picture showing the milk-like appearance and presence of casein clots in the ruminal fluid of a calf with acute ruminal drinking.

\section{Discussion}

We hypothesized that acute $\mathrm{RD}$ might trigger an inflammatory response in milk-fed calves. In the present study, the clinical characteristics and biochemical alterations associated with RD in the diseased calves were similar to previous reports $[1,2]$. It was also found that a single episode of $\mathrm{RD}$ was responsible for only transitory acid production that did not produce noteworthy clinical repercussions. As soon as the fermentable substrate was emptied or removed, the rumen regained its physiological $\mathrm{pH}(\mathrm{n}=5)$. However, when fermentable carbohydrates are persistently present in the rumen, acidification persists and gradually causes various metabolic alterations. Similar findings were previously reported by other researchers [19]. Interestingly, the diseased calves had increased blood L-lactate levels in spite of lacking the availability of measuring D-lactate. It is suggested that the increased anion gap indicates that L-lactic acid was partly responsible for the acidosis, rather than merely being loss of bicarbonate or retention of hydrogen ions [20]. This finding is unlike to that previously obtained by other reports $[19,21]$. Although blood L-Lactate can be metabolized quickly by the calves, its high concentration indicates continuous influx into the bloodstream.

Several APPs have just begun to be tackled by bovine researchers and more research is required to uncover the role that APPs play in host innate immunity. APPs have been proposed as good markers of acidosis in cattle [22]. To our knowledge; however, this is the first article describing the changes of APPs and cytokine responses during acute $\mathrm{RD}$ in milk-fed calves. It was found that plasma Hp and CRP, but not fibrinogen, increased more than 20-fold in diseased calves compared to control calves. These findings were in part similar to previous reports in steers and goats with experimental ruminal acidosis [22,23]. We suggest that Hp and CRP might be useful markers for detecting the severity of acute RD in milk-fed calves, however, understanding the mechanism behind the increase in Hp and CRP in diseased calves as well as consequences for the general health warrant further investigations. The correlations between L-lactate, pro-inflammatory cytokines and APPs in the blood suggest that acute ruminal and systemic acidosis resulted in production of acute phase cytokines in diseased calves. The increased levels of pro-inflammatory cytokines are a result of ruminitis caused by ruminal acidosis. This finding partly agrees with recently published articles on experimentally induced ruminal acidosis in goats and cattle $[23,24]$.
In the present study, the positive correlations between depression scores and examined variables suggest that this scoring system is useful to evaluate metabolic acidosis and associated inflammatory responses in calves with acute RD. Similar findings were reported in Japanese calves with diarrhea [15]. The positive correlation between depression score and examined cytokines also support the previously developed theory which postulated that depression in humans may be caused by cytokine secretion associated with activation of the immune system [25]. The understanding of the interactions between the brain and the immune system has increased dramatically in the past ten years since Hart published his article describing the biological basis for sickness behavior [26]. The important argument made by Hart was that the behavior patterns of the sick animals are not maladaptive responses, whereas some evidence suggests that the decreased feed intake in response to disease challenge is adaptive in growing domestic food animals [27]. We suggest that the production of acute phase cytokines, together with metabolic acidosis, is a possible cause of depression in calves with acute $\mathrm{RD}$; however, their pathophysiologic mechanism is still a matter of debate.

\section{Conclusion}

Our findings suggest that the acidity of the rumen has led to ruminal papillae inflammation with subsequent distinct production of APPs and pro-inflammatory cytokines. It seems that the pro-inflammatory cytokines play a role in the pathogenesis of acute $\mathrm{RD}$ in milk fed calves.

\section{Conflict of Interest Statement}

The authors of this paper have no financial or personal relationship with other people or organizations that could appropriately influence or bias the content of the paper.

\section{References}

1. van Weeren-Keverling Buisman $A$, Wensing $T$, van den Ingh TSGAM, Breukink HJ (1990) Intraruminal administration of milk in the calf as a model for rumina drinking: Clinical aspects and biochemical and morphological changes in the rumen. J Anim Physiol Anim Nutr 63: 255-266.

2. Gentile A (1995) Acidity of the rumen liquid of calves after intra-rumina administration of solutions for oral rehydration. Dtsch Tierarztl Wochenschr 102: $241-244$

3. Gentile A, Rademacher G, Seemann G, Klee W (1998) Systemic effects of ruminal acidosis following ruminal drinking in dairy calves. A retrospective analysis of 293 cases. Tierarztl Prax Ausg G Grosstiere Nutztiere 26: 205-209.

4. Herrli-Gygi M, Steiner A, Doherr MG, Blum JW, Kirchhofer M, et al. (2008) Digestive processes in ruminal drinkers characterized by means of the acetaminophen absorption test. Vet J 176: 369-377.

5. Aiello SE (2005) The Merck Veterinary Manual. (9thedn), Merck \& Co., Inc Philadelphia, Pensylvania, USA.

6. Dirr L, Dirksen G (1989) Dysfunction of the esophageal groove ("ruminal drinking") as a complication of neonatal diarrhea in the calf. Tierarztl Prax 17 353-358.

7. Stocker H, Lutz P, Rosch $P$ (1999) Clinical, haematological and biochemical findings in milk-fed calves with chronic indigestion. Vet Rec 145: 307-311.

8. Dunlop RH (1972) Pathogenesis of ruminant lactic acidosis. Adv Vet Sci Comp Med 16: 259-302.

9. Gentile A, Rademacher G, Klee W (1997) Acidosi ruminale fermentativa ne vitello lattante. Ob Doc Vet 18: 63-75.

10. Mackiewicz A (1997) Acute phase proteins and transformed cells. Int Rev Cyto 170: $225-300$

11. Koj A (1998) Termination of acute-phase response: role of some cytokines and anti-inflammatory drugs. Gen Pharmacol 31: 9-18.

12. Martin F, Santolaria F, Batista N, Milena A, Gonzalez-Reimers E, et al. (1999) 
Citation: El-Ashker M, El-Sebaei M, Salama M (2012) Evaluation of the Inflammatory Reaction in Calves with Acute Ruminal Drinking. J Vet Sci Technol 3:116 doi:10.4172/2157-7579.1000116

Page 5 of 5

Cytokine levels (IL-6 and INF-gamma), acute phase response and nutritional status as prognostic factors in lung cancer. Cytokine 11: 80-86.

13. Ohzato H, Yoshizaki K, Nishimoto N, Ogata A, Tagoh H, et al. (1992) Interleukin-6 as a new indicator of inflammatory status: detection of serum levels of interleukin-6 and C-reactive protein after surgery. Surgery 111: 201209.

14. Segreti J, Gheusi G, Dantzer R, Kelley KW, Johnson RW (1997) Defect in interleukin-1beta secretion prevents sickness behavior in $\mathrm{C} 3 \mathrm{H} / \mathrm{HeJ}$ mice. Physiol Behav 61: 873-878

15. Nakagawa M, Suzuki K, Taguchi K (2007) Relationship between depression score and acid base status in Japanese Black calves with diarrhea. J Vet Med Sci 69: 549-552.

16. Kasari TR (1999) Metabolic acidosis in calves. Vet Clin North Am Food Anim Pract 15: 473-486.

17. Odbileg R, Konnai S, Ohashi K, Onuma M (2005) Molecular cloning and phylogenetic analysis of inflammatory cytokines of Camelidae (llama and camel). J Vet Med Sci 67: 921-925.

18. Odbileg R, Purevtseren B, Batsukh Z, Konnai S, Ohashi K, et al. (2006) Complete cDNA sequences and phylogenetic analyses of the Th1 and Th2 cytokines of the bactrian camel (Camelus bactrianus). J Vet Med Sci 68: 941946.

19. Gentile A, Sconza S, Otranto G, Bergamini F, Rademacher G, et al. (2000) Clinical and metabolic consequences of an experimentally induced ruminal acidosis in veal calves. Italian Association for Buiatrics. Annual meeting,
Alghero, Sassari (Italy), 11-12 May. 33: 225-240.

20. Guyton AC (1981) Textbook of medical physiology. (6thedn), WB Saunders Philadelphia, USA

21. Gentile A, Sconza S, Lorenz I, Otranto G, Rademacher G, et al. (2004) D-lactic acidosis in calves as a consequence of experimentally induced ruminal acidosis. J Vet Med A Physiol Pathol Clin Med 51: 64-70.

22. Gozho GN, Krause DO, Plaizier JC (2006) Rumen lipopolysaccharide and inflammation during grain adaptation and subacute ruminal acidosis in steers. J Dairy Sci 89: 4404-4413.

23. Gozalelz FHD, Ruiperez FH, Sanches JM, Sanza JC, Marinez-subield S, et al (2010) Haptoglobin and serum amyloid A in subacute ruminal acidosis in goats. Rev Med Vet Zoot 57.

24. Danscher AM, Thoefner MB, Heegaard PMH, Ekstrøm CT, Jacobsen S (2011) Acute phase protein response during acute ruminal acidosis in cattle. Livestock Sci 135: 62-69.

25. Smith RS (1991) The macrophage theory of depression. Med Hypotheses 35 298-306.

26. Hart BL (1988) Biological basis of the behavior of sick animals. Neurosci Biobehav Rev 12:123-137.

27. Williams NH, Stahly TS, Zimmerman DR (1997) Effect of level of chronic immune system activation on the growth and dietary lysine needs of pigs fed from 6 to $112 \mathrm{~kg}$. J Anim Sci 75: 2481-2496. 